\title{
DEVELOPMENT OF METHOD FOR ANALYSIS AND QUANTIFICATION OF CEFADROXIL IN DIFFERENT PHARMACEUTICAL FORMULATIONS USING HPLC
}

\author{
Viswanath Vittaladevaram* and Hemanth Pragada \\ 1,2 Jain Institute of Vocational and Advanced Studies, \#127/3, Bull Temple Road,Chamarajpet, Bangalore- \\ 560019
}

\begin{abstract}
*Corresponding Author Email: viswa.vittal@gmail.com
ABSTRACT

A rapid, accurate and sensitive method has been developed for the quantitative determination of Cefadroxil (first generation) in different pharmaceutical formulations. An C-18 ODS, 4.60*250 micro meter analytical column was used with an eluting system consisting of a mixture of phosphate buffer ( $\mathrm{pH}$ 4.8)-Methanol-Acetonitrile 95-3-2 \%( $v / v$ ) at a flow rate $1 \mathrm{ml} / \mathrm{min}$. Detection was performed by UV-Vis Detector at 230nm, for Cefadroxil per 20microlitre injection. The proposed method is suited both for the determination of Cephalosporins in a wide variety of commercial dosage forms and for the investigation of related compounds and other impurities in Cephalosporins.
\end{abstract}

\section{KEY WORDS}

Cefadroxil, C 18 ODS Column, Chromatogram, Retention time

\section{INTRODUCTION:}

Cefadroxil is semi synthetic antibiotic classified under Cephalosporin group of pharmaceuticals. Cefadroxil exhibits antibacterial property and it is used for treatment of susceptible bacterial infections such as Strep throat which is caused mainly due to
Streptococcus pyogenes bacteria. Chemically it is designated as 5-thia-1-azabicyclo [4.2.0] oct-2-enecarboxylic acid, 7- [[amino (4-hydroxyphenyl) acetyl] amino]-3-methyl-8-oxo-, monohydrate, [6R- [6alpha, 7 beta $\left.\left(R^{*}\right)\right]$ ]- [1-7]. The chemical structure of the Cefadroxil is illustrated below in Figure 1.

Figure 1: Chemical structure of Cefadroxil

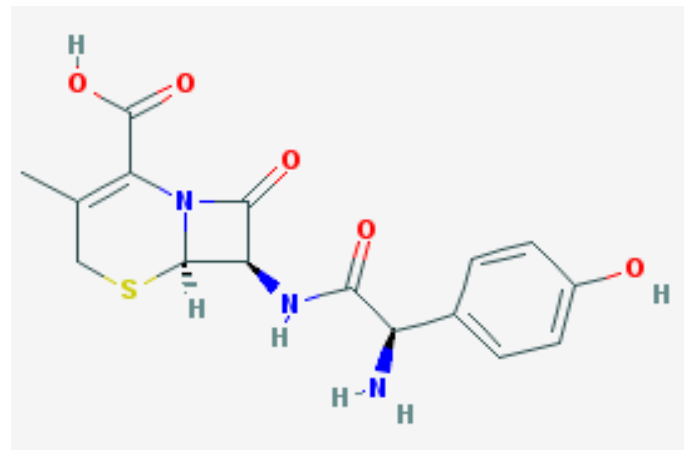

The molecular formula of Cefadroxil is $\mathrm{C} 16 \mathrm{H} 17 \mathrm{~N} 305 \mathrm{~S}$ and molecular weight of the compound is 363.38 $\mathrm{g} / \mathrm{mol}$. Cefadroxil is available in the form of capsules which are primarily used for the treatment of skin infections caused due to Streptococci and Staphylococci species [1-4]. In addition to this Cefadroxil is used for urinary tract infections caused by E.coli, Proteus mirabilis and klebsiella species. The half-life time of Cefadroxil is 1.5 hours. The review of literature suggested that quantification of Cefadroxil was reported in biological fluids (human blood serum and urine) [2, 4, 7] and pharmaceutical compounds [2-7]. All these methods used liquid chromatography procedures specifically 
by using HPLC (High performance liquid chromatography) and also indicated that best results were observed by application of reverse phase High performance liquid chromatography (RP-HPLC) procedures. Literature review studies indicated that all these methods still require changes with regard to mobile phase composition, flow rate since they are found to be not efficient and economical.

\section{Materials and Method:}

\subsection{Aim and Objective:}

To develop a method for the analysis and quantification of Cefadroxil in different pharmaceutical formulations.

\subsection{Instrumentation and Software:}

Waters HPLC system is used for development of method and validation of Cefadroxil. By using Breeze system software version 3.3 signal output is carefully monitored and processed.

\subsection{Requirements:}

\subsubsection{Materials required:}

Column: Waters, C18, 4.6*150mm, 5 micrometer, symmetry, stainless steel

Detector: Waters 2487, Dual absorbance detector Pump: Waters 1525 Binary HPLC pump

Filters: 0.2 micrometer, 47 millimeter

\subsubsection{Chemicals required:}

All chemicals and reagents used for the experiment were of HPLC grade

Acetonitrile (HPLC grade), Methanol, Acetic acid, Monobasic Potassium Phosphate, Orthophosphoric acid, Cefadroxil standard, Milli-Q-Purified water

\subsubsection{Other requirements:}

Vacuum pump, Sonicator, pH Pen, Weight balance, Tissue paper, reagent bottles, volumetric flasks $(10 \mathrm{ml})$, Spatula, Syringe, beakers, micropipette, microtips, distilled water.

\subsubsection{Preparation of Mobile Phase:}

Solution A: $\quad 20 \mathrm{mM}$ monobasic
PotassiumdihydrogenPhosphate was dissolved in $1000 \mathrm{ml}$ of distilled water. To this $1 \mathrm{ml}$ of acetic acid is added and thoroughly mixed. The $\mathrm{pH}$ of the solution was adjusted to 4.8 using orthophosphoric acid and solution was mixed and filtered to remove impurities present in the form of gas bubbles.

Solution B: This solution contains only Methanol. Solution C: This solution contains only Acetonitrile.

Sample solvent: The sample solvent is comprised of mobile phase $A$ : $B$ : $C$ (solutions) present in the ratio of $95: 3: 2(\% \mathrm{v} / \mathrm{v})$.

\subsection{Conditions of Chromatography:}

An C-18 ODS $(4.60 \mathrm{~mm} \times 250 \mathrm{~mm})$ analytical column was used with an eluting system consisting of a mixture of phosphate buffer (pH 4.8)-MethanolAcetonitrile 95-3-2 \%( $\mathrm{v} / \mathrm{v})$ at a flow rate $1 \mathrm{~mL} / \mathrm{min}$. The injection volume was $20 \mu \mathrm{L}$ and concentration of working solution is $2 \mu \mathrm{g} / \mathrm{mL}$. Ambient temperature is maintained and detection was performed by using UV-Visible detector at $230 \mathrm{~nm}$ for a runtime of $10 \mathrm{~min}$.The retention time of Cefadroxil was $4.17 \mathrm{~min}$.

\subsection{Sample Preparation}

2.5.1 Standard Stock Preparation: $4 \mathrm{mg}$ equivalent of Cefadroxil in $10 \mathrm{~mL}$ volumetric flask. Then make up the volume with mobile phase and sonicate it. 2.5.2 Preparation of working sample: From the standard stock $50 \mu \mathrm{L}$ is transferred to volumetric flask. Then make up the volume with mobile phase and filter the solution and inject $20 \mu \mathrm{L}$ into the pump.

\section{RESULTS AND DISCUSSION:}

3.1 Optimization for chromatographic conditions: To optimize the mobile phase for developing the method for standard Cefadroxil we selected C-18 ODS $(4.60 \times 250 \mu \mathrm{m})$ analytical column in order to reduce the retention time and also to obtain good peaks which are found to be symmetric and exhibit better resolution. The mobile phase is composed of mixture of phosphate buffer ( $\mathrm{pH} 4.8)$ Methanol-Acetonitrile 95-3-2 \%( v/v) gave good peak tip and both retention time and area is found to be reproducible. The retention time of Cefadroxil was found to be $4.17 \mathrm{~min}$.The HPLC chromatogram of standard Cefadroxil was depicted in Figure 2. 
Figure 2: HPLC Chromatogram of Standard Cefadroxil

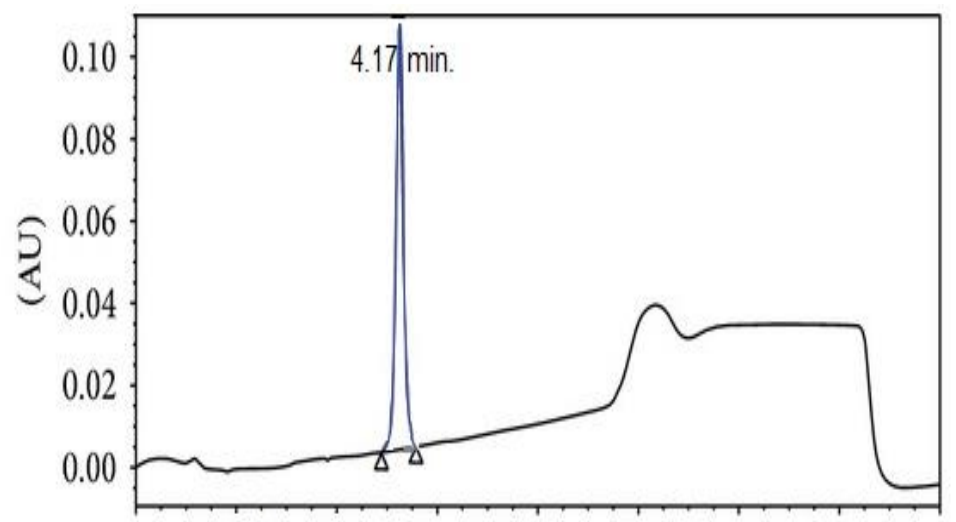

0.001 .002 .003 .004 .005 .006 .007 .008 .009 .0010 .00

(min)

Figure 3: Calibration curve of Cefadroxil

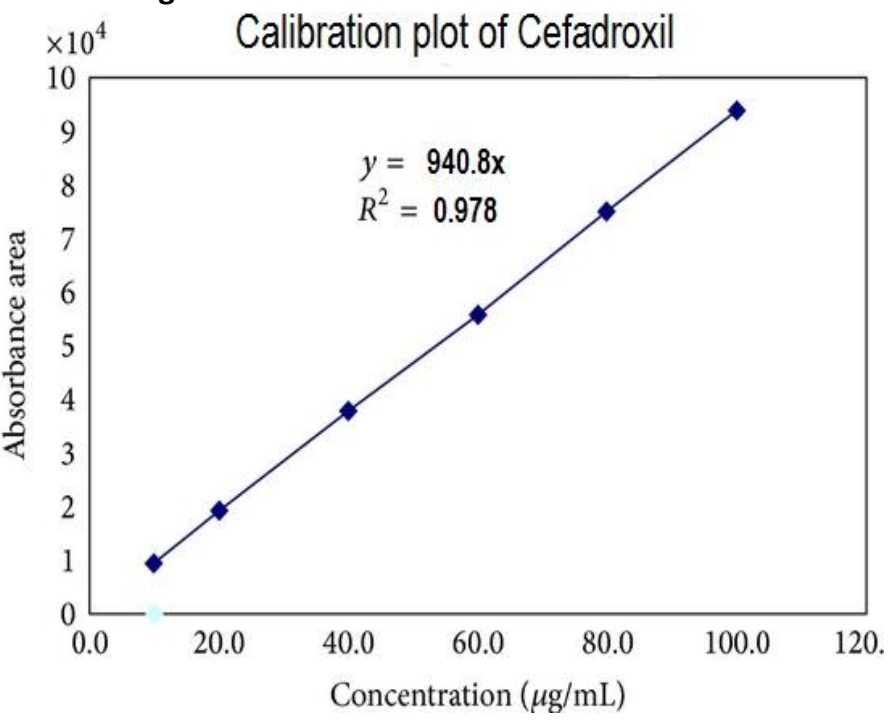

\subsection{Method Validation:}

As per $\mathrm{ICH}$ guidelines the method proposed was validated based on parameters include linearity, accuracy and precision.

\subsection{Linearity Plot Analysis:}

By using stock solution linearity plot analysis for Cefadroxil were prepared with different (10-100 $(\mu \mathrm{g} / \mathrm{mL}))$ concentration levels. The curves were calibrated by plotting concentrations versus peak area. The values of correlation coefficient, $Y$ intercept and slope were worked out and value of correlation coefficient is 0.978. The calibration curve is shown in Figure 3.

\subsection{Accuracy Estimation:}

Recovery analysis procedure was carried out to determine the quality of method and its implementation at different percentage levels include $50 \%, 100 \%$ and $150 \%$ were added. The percentage recovery at three different levels was calculated for Cefadroxil by sample injection. The results were shown in Table 1.

3.5 Precision studies: The standard concentration of Cefadroxil is injected for five times into the column to evaluate the precision by following same chromatographic parameters and percentage of relative standard deviation (\%RSD) is calculated The \%RSD will determine the method is reiterated. The \% RSD for Cefadroxil assay is 1.01.The results were displayed in Table 2 .

3.6 Assay of Cefadroxil Pharmaceutical Formulation: The method proposed is validated and applied for determination of Cefadroxil which is available in tablet dosage form successfully. The results show percentage of Cefadroxil retained and 
compared with amounts that are labeled are presented in Table 3.

Table 1: Accuracy estimation

\begin{tabular}{|c|c|c|c|c|c|}
\hline Analyte & $\begin{array}{l}\text { Percentage } \\
\text { level }\end{array}$ & $\begin{array}{l}\text { Nominal value } \\
\text { (mg) }\end{array}$ & $\begin{array}{l}\text { Amount } \\
\text { present } \\
\text { (mg) }\end{array}$ & $\begin{array}{l}\text { percentage of } \\
\text { recovery }\end{array}$ & $\begin{array}{l}\text { Mean percentage } \\
\text { recovery }\end{array}$ \\
\hline & $50 \%$ & 2.5 & 2.42 & 96.8 & \\
\hline \multirow[t]{2}{*}{ Cefadroxil } & $100 \%$ & 5 & 4.97 & 99.4 & 96.42 \\
\hline & $150 \%$ & 7.5 & 6.98 & 93.06 & \\
\hline
\end{tabular}

Table 2: Precision results

\begin{tabular}{lll}
\hline Injections & Precision & Precision at intermediate level \\
\hline 1 & 35584 & 34378 \\
2 & 34625 & 35648 \\
3 & 35148 & 34236 \\
4 & 35012 & 33634 \\
5 & 34867 & 34287 \\
Average & 35047 & 34436 \\
Standard deviation & 357.16 & 737.85 \\
$\%$ RSD & 1.01 & 2.14 \\
\hline
\end{tabular}

Table 3: Results of Assay

\begin{tabular}{llll}
\hline Compound & Label claim (mg) & Amount present $(\mathbf{m g})$ & Percentage(\%) of Assay \\
\hline Cefadroxil & 5.0 & 4.92 & 98.4 \\
\hline
\end{tabular}

\section{CONCLUSION:}

The proposed method found to be most accurate and precise. The method developed and validated in terms of linearity, accuracy and precision for Cefadroxil in different pharmaceutical formulations. The method gave good reproducible retention time and area. The recovery percentage indicates that method developed is free from impurities that are used in the pharmaceutical formulation and thus it clearly suggests that method can be used for Cefadroxil analysis present in either bulk or tablet dosage forms in laboratories.

\section{ACKNOWLEDGEMENT:}

We are grateful to Jain Institute of Vocational and Advanced Studies, Jain Group of Institutions, Bangalore, India for providing all facilities to conduct this experiment successfully.

\section{REFERENCES:}

1. Asha C and Narayana B., A Simple Method for the Spectrophotometric Determination of
Cephalosporins in Pharmaceuticals using Variamine Blue, Ecl. Quim., Sao Paulo, 33(2), 41-46, (2008)

2. Devaliya $R$ annd Jain U., Noval estimation of cefadroxil in tablet dosage forms by RP-HPLC. Orient J Chem, 25(4): 1053, (2009).

3. El-Shaboury S. R., Saleh G. A., Mohamed F. A. and Rageh A.H., Analysis of Cephalosporin Antibiotics. J. Pharmaceut. Biomed. Anal., 45, 1-19,(2007).

4. Espinosa Boscha M, Ruiz Sanchezb A J, Sánchez Rojasc $F$ and Bosch Ojeda C., "Recent developments in the analytical determination of cefadroxil, "Asian Journal of Pharmaceutical Sciences, 3(5), 217-232, (2008).

5. Malathi S, Dubey RN, \& Venkatnarayanan R., Simultaneous RP-HPLC estimation of Cefpodoxime proxetile and clavulanic acid in tablet. Indian Journal of Pharmaceutical science, 71(1), 102-105, (2009).

6. Ravi S Shukla, Asha patel, Soni M L, Vishesh modi \& Jaliwala Y A., "Quantitative spectrophotometric estimation of cefadroxil using hydrotropic solubilization technique, Asian Pharmaceutics, 2(3), 146-147, (2008).

7. Shukla RS, Pandey $S$, Bargale $R$, Pateland A \& Tiwari M., Novel HPLC analysis of cefadroxil in bulk formulation. Asian J. Pharmaceut, 2(2), 106, (2008). 
*Corresponding Author:

Viswanath Vittaladevaram* and Hemanth Pragada

Email:viswa.vittal@gmail.com 